\title{
100 years and counting
}

\author{
Jeffrey Turnbull MD
}

Jeffrey Turnbull is president, CMA.

CMAJ 2011. DOI:10.1503 /cmaj.101779

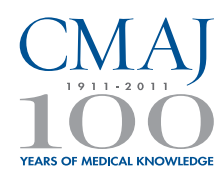

A s the first issue of CMAJ was being mailed in January 1911, editors at The Globe in Toronto - it would not be known as The Globe and Mail until 1936 — had just published their first editorial of the year.

"To be a Canadian in 1911," they wrote, "is to be given a chance which is matched only by an unprecedented obligation."

I believe the first editor of CMAJ, Sir Andrew Macphail, must have read those words.

Anyone looking through the 12 issues of the journal published that year, or through the hundreds published since then, will know that Macphail and his 16 successors accepted an "unprecedented obligation" of their own by agreeing to serve as editor of our journal.

For the past 100 years, CMAJ has not only functioned as the record keeper for the medical profession in Canada, but it has also been the link uniting a relatively small number of doctors spread across a huge country. In 1911, it delivered the message that we are all part of a team. In 2011, it is still doing the same thing.

Andrew Macphail wrote that he helped launch CMAJ in order to provide "a medium for the expression of all that is best in Canadian medicine."

He could not have known it at the time, but his brand new journal would also develop into one of the country's most important windows for looking out onto Canadian society. It did this by becoming Canada's storehouse for information on the impact of health policy, war, infectious disease, abject poverty, medical advances and so much more.

In the process, it attracted our top medical minds as contributors - Osler, Maude Abbott, Banting, Best, Bruce Chown, Henry Barnett, David Sackett, and so many more. Indeed, if you check the list of laureates at Canada's Medical Hall of Fame, you will almost invariably find the same names in the list of CMAJ authors.

This is also a journal that punched above its weight in terms of the ideas it presented.

Although "population health" would not enter the medical lexicon for many years, $C M A J$ editors appear to have been aware of the concept from the start. Thus, our colleagues (and governments) of 100 years ago were challenged to act on issues such as infant mortality rates that, today, seem absurdly high.

These constant reminders to physicians "to do better" have now continued for a century, and as a profession we are better for them.

Many of us, after being introduced to CMAJ at medical school, became familiar with new concepts such as evidence-based medicine, which were promoted by the journal. I have been learning lessons for more than 30 years.

So what does the future hold?

In 1911, CMAJ was delivered by mail to about 1500 doctors spread across the country. Today, that number stands at 71 000. In 1995, this same journal spread its digital wings for the first time. Today the online version receives more than 30 million requests a year from all parts of the world - exposure that has earned it considerable international recognition.

Change has also brought some difficulties, including the need to develop a new business model as the switch from paper-based to digital publishing gathers steam. Work on developing this new model is well underway, just as it is at many other journals and newspapers. However, that is a discussion for another time.

In January 2011, it's time to celebrate the centennial of the CMA's crown jewel - a journal that was born as humans experimented with powered flight and is turning 100 as an international space station circles the globe. We have witnessed the same breadth of change in medicine, and our guide through all of it has been CMAJ.

On behalf of all 74000 CMA members, it gives me great pleasure to congratulate our journal as it turns 100 , and to recognize the staff members — past and present - who made this possible. You have served us well.

Finally, I hope that CMAJ's second century proves as successful as the first. I have no doubts that it will. 